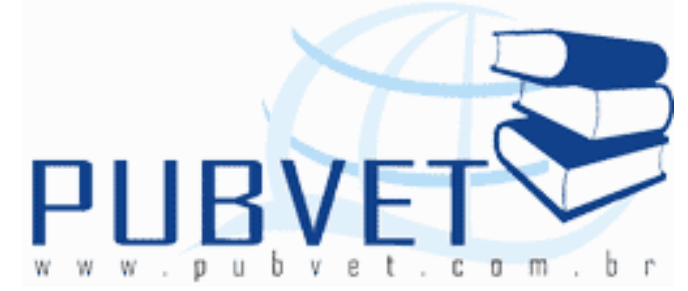

PUBVET, Publicações em Medicina Veterinária e Zootecnia.

\title{
Efeito da escarificação, da embebição e da adubação nitrogenada no crescimento inicial do labe-labe (Dolichos lab lab L. cv. RONGAI)
}

João Elzeário Castelo Branco Iapichini ${ }^{1}$, Carlos Frederico de Carvalho Rodrigues ${ }^{1}$, Antonio Orlando da Luz Freire Neto ${ }^{2}$, Cláudio Henrique Barbosa Monteiro $^{2}$

${ }^{1}$ Pesquisador Científico da Secretaria da Agricultura do Estado de São Paulo (APTA/S.A.A).

${ }^{2}$ Pesquisador Científico da Secretaria do Meio Ambiente (IF/SMA).

\section{Resumo}

A introdução de leguminosas forrageiras em programas de melhoramento de pastagens tem sido preconizada, como uma das formas mais econômicas, para obtenção do nitrogênio, tão essencial para a melhoria da dieta animal, assim como para a obtenção de altos rendimentos de forragens. $O$ trabalho experimental foi instalado em vasos, em casa de vegetação, na Faculdade de Ciências Agrárias e Veterinárias "Campus" de Jaboticabal. Adotou-se o delineamento experimental inteiramente casualizado, para se estudar um arranjo fatorial $2 \times 3 \times 2$ com 3 repetições. Os tratamentos consistiram em diferentes combinações de escarificação e não escarificação de sementes e tempos de embebição das sementes antes da semeadura (1, 8 e 16 horas) e ausência e presença de adubação nitrogenada (0 e $100 \mathrm{~kg}$ de $\mathrm{N} / \mathrm{ha}$ ). Os resultados obtidos mostraram que a escarificação das sementes seguida da 
imersão por 1 hora, ou somente a imersão por 8 horas, poderia resultar em germinação mais rápida. $O$ crescimento inicial do labe-labe, independentemente dos tratamentos testados, foi bastante vigoroso. A altura média das plantas não variou em função dos diferentes tratamentos. A distribuição e a produção de matéria seca na parte aérea da planta, após 61 dias da semeadura, foi bastante uniforme nos diferentes tratamentos. A aplicação de nitrogênio, 16 dias após a semeadura, prejudicou significativamente o peso seco dos nódulos.

\title{
Effect of scarification, soaking and of nitrogen in the initial growth of labe-labe (Dolichos lab lab L. cv. RONGAI).
}

\begin{abstract}
The present work was carried out in a Green house at the Faculdade de Ciências Agrárias e Veterinárias de Jaboticabal. Twelve treatments arranged in a factorial way $2 \times 3 \times 2$, were randomized in 3 replications to study the inicial growth of labe-labe. The treatments studied were: seed treatment (with and without sandpapes numer 2); times of soaking (1, 8 and 16 hours) and nitrogen levels ( 0 and $100 \mathrm{~kg}$ of $\mathrm{N} / \mathrm{ha}$ ). The nitrogen was apllied 16 days after the sowing. The results obtained suggested that the treatments of the seeds followed by soaking for 1 hour or only the soaking by 8 hours could result in a more rapidly germination. Inicial growth of $l a b$ lab was vigorous independently of treatments. Average height of plants did not vary with the treatments. Distribution and dry matter production of the aerial part, after 61 days of sowing, were very uniform in all treatments. The application of nitrogen, 16 days after sowing, decreased significantly the dry weight of nodules.
\end{abstract}

\section{1 - INTRODUÇÃO}

A introdução de leguminosas forrageiras em programas de melhoramento de pastagens tem sido preconizada, como uma das formas mais 
econômicas, para obtenção do nitrogênio, tão essencial para a melhoria da dieta animal, assim como para a obtenção de altos rendimentos de forragens.

Na fase inicial de estabelecimento da cultura, a rapidez de germinação e uniformidade de crescimento são fatores de grande importância, pois habilitam as plantas a competir igualmente por água, luz e nutrientes (DONALD, 1963)

Uma das prováveis causas da falta de germinação das sementes, verificada para a espécie, é o fenômeno da dormência, que pode ser conceituado como o estado de repouso fisiológico em que a semente, em razão da ação de fatores internos, apresenta mecanismos bloqueadores da germinação. A dormência se encerra quando o metabolismo, síntese e crescimento ativos são reiniciados (Marcos Filho, 2005).

Para que ocorra a quebra da dormência induzida, as sementes devem ser submetidas a tratamentos de estratificação e imersão em soluções antes da semeadura para aumentar a taxa de germinação (VEIGA, 2003).

Entre os métodos utilizados para superação da dormência tegumentar, a escarificação mecânica é uma técnica frequentemente utilizada e constitui a opção mais prática e segura para pequenos agricultores (Hermansen et al., 2000), além de ser um método simples, de baixo custo e eficaz para promover uma rápida e uniforme germinação. No entanto, deve ser efetuada com muito cuidado para evitar que a escarificação excessiva possa causar danos ao tegumento e diminuir a germinação (McDonald e Copeland, 1997). A escarificação mecânica do tegumento foi eficiente na superação da dormência das sementes de várias espécies com tegumento impermeável, como as de Erythrina velutina Willd. (Silva e Matos, 1993), Psidium araça Raddi (Cruz et al., 1997), Paspalum paniculatum L. (Lula et al., 2000) e Sterculia foetida L. (Santos et al., 2004). Para superar a dormência, vários métodos podem ser utilizados, sendo os mais comuns: embebição em água, retirada do tegumento, desponte (corte do tegumento), furo do tegumento, escarificação mecânica, imersão em água quente ou fria, água oxigenada, escarificação química com ácido sulfúrico, ácido clorídrico, soda, acetona e álcool (Santarém e Áquila, 1995). 
A capacidade de fixar nitrogênio simbióticamente, através de bactérias do gênero Rhizobium, faz com que; de modo geral, as leguminosas não tenham o seu crescimento afetado pelo baixo teor de nitrogênio no solo.

Por outro lado, tem sido contraditórios os resultados obtidos com a aplicação de adubos nitrogenados, no estabelecimento de leguminosas forrageiras.

Assim, a aplicação de nitrogênio em plântulas de trevo branco, cultivadas em vasos, ocasionou um efeito positivo sobre a produção de matéria seca e um efeito depressivo na quantidade de nitrogênio fixado, exceto quando a dose de nitrogênio foi baixa (ALLOS \& BARTHOLOMEW, 1959).

A aplicação de nitrogênio resultou em aumento da produção de matéria seca de Medicago híspida var. confinis, quando foram feitas quatro aplicações de $40 \mathrm{~kg}$ de N/ha, durante o período de crescimento. Todavia, o número de nódulos foi, no geral, reduzido em decorrência da adubação nitrogenada (CARÁMBULA, 1967).

A soja perene, adubada com $125 \mathrm{~kg}$ de $\mathrm{H} / \mathrm{ha}$, mostrou aumento de crescimento com a elevação de temperatura do solo; entretanto, o peso dos nódulos e a assimilação de nitrogênio foram drasticamente reduzido (SOUTO \& DEBEREINER, 1970).

Na Austrália, a aplicação de $28 \mathrm{~kg}$ de N/ha, 9 ou 18 dias após a semeadura, não teve efeito significativo no crescimento ou nodulação de sojaperene (Glycine wightii), e de siratro (Macroptilium atropurpureum) (WHYTEMAN, 1972).

Na Austrália, COOKSLEY (1974) trabalhando com Leucena leucocephala (Lam.) de Wit, cv. peru, fez aplicações de 22 a $45 \mathrm{~kg}$ de N/ha sob a forma de sulfato de amônio, 13 dias antes da semeadura. A adição de nitrogênio não teve efeito significativo no número de plantas estabelecidas e na produção de matéria seca da forragem, tendo favorecido o crescimento de invasores.

MATTOS \& CAMPOS (1975), estudando o efeito do nitrogênio mineral no desenvolvimento inicial, produção de matéria seca e nodulação da soja perene (Glycine wightii) observaram, que os tratamentos, com e sem 
nitrogênio, não diferiram quanto a produção de matéria seca, observando-se a mesma tendência com relação a massa nodular.

O labe-labe (Dolichos lab lab L.), cultivado na Ásia desde a antiguidade para alimentação humana, é planta de fácil estabelecimento e que se adapta a diferentes tipos de clima e solo.

Marcante publicação sumariza suas múltiplas qualidades e opções de uso, e realça seu potencial como planta forrageira para as regiões tropicais (NATIONAL ACADEMY OF SCIENCES, 1979). Mais de 200 genótipos são conhecidos os quais, além de apresentar variação na cor, forma e tamanho das folhas, flores, vagens e sementes, podem apresentar diferenças fisiológicas relacionadas com o vigor de plântulas, tolerância a seca, época de florescimento, viabilidade das sementes, etc.

Entretanto, mesmo para as variedades comerciais existentes, são escassas informações que permitam uma utilização mais ampla do labe-labe como planta forrageira. A literatura consultada não aponta a necessidade de se escarificar as sementes do labe-labe, porém enfatiza a necessidade de pesquisas que avaliem aspectos relacionados com a nodulação a quantidade de nitrogênio fixado (NATIONAL ACADEMY OF SCIENCES, 1979).

O presente trabalho teve por objetivo verificar os efeitos da escarificação e embebição das sementes e da aplicação de nitrogênio, sobre o crescimento inicial da variedade Rongai da labe-labe.

\section{2 - MATERIAL E MÉTODOS}

O presente trabalho experimental foi conduzido em casa de vegetação, na Faculdade de Ciências Agrárias e Veterinárias - "Campus" de Jaboticabal, no município de Jaboticabal, São Paulo, Brasil (211` $22^{\prime}$ 'de latitude Sul, $48^{\circ} 18^{`} 58^{\prime}$ 'de longitude Oeste, altitude média de $595 \mathrm{~m}$ ), durante os meses de agosto a novembro de 1979.

A figura 1 mostra uma vista geral do experimento, 39 dias após a semeadura. 


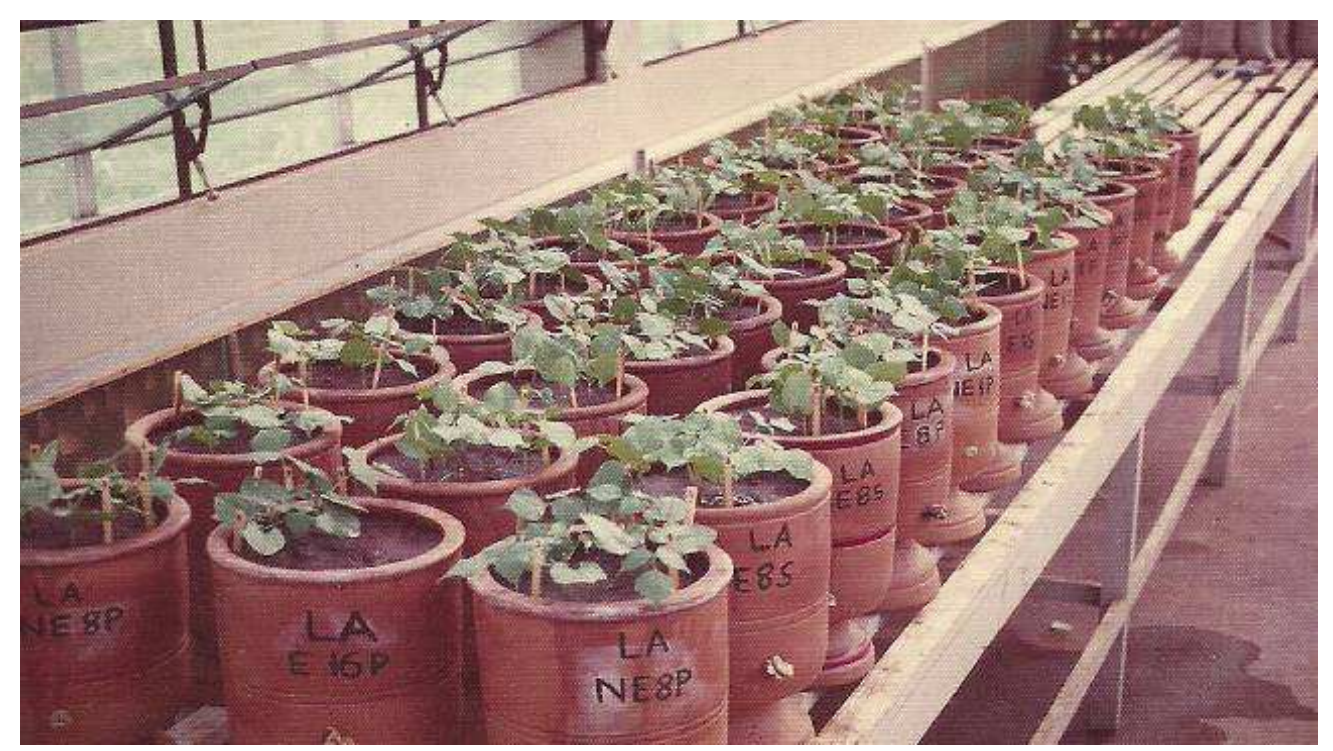

Figura 1: Vista geral do experimento, 39 dias após a semeadura.

O experimento foi instalado segundo um delineamento experimental inteiramente casualizado, com 12 tratamentos e 3 repetições.

Os tratamentos consistiram de escarificação das sementes com lixa no 2; sementes não escarificadas; ambas em diferentes combinações de tempos de embebição das sementes antes da semeadura durante 1 , 8 e 16 horas em água destilada; ausência e presença de adubação nitrogenada (100 $\mathrm{kg} \mathrm{N} / \mathrm{ha}$ ).

O solo utilizado foi um Latossol Vermelho-Escuro, fase arenosa, cuja análise química é mostrada no Quadro 1.

Quadro 1 - Analise química do solo utilizado.

\begin{tabular}{|l|l|l|l|l|l|l|}
\hline \multirow{2}{*}{$\% \mathrm{C}$} & $\mathrm{pH}$ & \multicolumn{2}{|l|}{$\mu \mathrm{g} / \mathrm{ml}$ T.F.S.A } & \multicolumn{3}{|l|}{ Emg/100 ml T.F.S.A } \\
\cline { 2 - 7 } & $\mathrm{H}_{2} \mathrm{O}$ & $\mathrm{P}$ & $\mathrm{K}$ & $\mathrm{Al}+++$ & $\mathrm{Ca}++$ & $\mathrm{Mg}++$ \\
\hline 0,80 & 5,9 & 10 & 64 & 0 & 1,5 & 0,7 \\
\hline
\end{tabular}

O solo utilizado como substrato foi secado à sombra e posteriormente homogeneizado e peneirado, para enchimento dos vasos. Os mesmos eram de cerâmica e tinham capacidade para $10 \mathrm{~kg}$ de solo seco. Para controlar 
possíveis efeitos da luminosidade no desenvolvimento das plantas, foi realizado o rodízio de posição dos vasos de 3 em 3 dias e mantida uma certa distância entre eles, com a finalidade de se evitar o sombreamento das plantas.

O volume e o peso médio de 100 sementes, submetidas aos vários tratamentos, foram mensurados, e da mesma forma, de 100 sementes secas, não escarificadas. Utilizou-se em cada um dos testes, 4 amostras de 100 sementes.

Ás 15 horas do dia 26 de agosto procedeu-se a semeadura do labelabe, distribuindo 10 sementes em cada um dos vasos a uma profundidade de 2 a $3 \mathrm{~cm}$, sendo que cada um dos vasos foi considerado uma repetição.

Os vasos foram regados diariamente com a mesma quantidade de água para manter o solo sempre próximo, ou na capacidade de campo.

As avaliações e coletas de dados nos vários tratamentos foram iniciadas no dia 03 de setembro, quando as primeiras plântulas emergiram na superfície do solo.

As avaliações e coletas de dados foram realizadas considerando-se vários estádios de crescimento, que foram definidos como segue:

10 - Aparecimento na superfície do solo (Emergência) ;

$2^{\circ}$ - Plântulas com os cotilédones fechados;

30 - Plântulas com os cotilédones abertos e o primeiro par de folhas fechado;

40 - Plântulas com o primeiro par de folhas aberto;

50 - Plantas com uma folha composta;

60 - Plantas com duas folhas compostas;

70 - Plantas com três folhas compostas;

80 - Plantas com quatro folhas compostas;

90 - Plantas com cinco folhas compostas;

$10^{0}$ - Plantas com seis a oito folhas compostas.

Quinze dias após a semeadura, foi realizado um desbaste nos vasos, deixando-se cinco plantas por vaso, recebendo cada vaso a quantidade de $2,7 \mathrm{~g}$ de sulfato de amônio. Para um melhor controle de medição da altura 
das plantas, as mesmas foram devidamente etiquetadas por ocasião do desbaste.

O experimento foi encerrado no dia 26 de outubro, sendo então coletados os dados de peso da matéria fresca das várias partes da planta, ou seja, dos pecíolos, caule, folhas de diferentes idades (mais novas e senescentes), raízes e nódulos radiculares.

As raízes foram separadas do solo, lavadas, secas com papel toalha e rapidamente pesadas. Os nódulos foram separados das raízes, contados e pesados. Em seguida todo o material vegetal foi colocado em estufa de circulação forçada, a $65-75^{\circ} \mathrm{C}$, até atingirem peso constante. Determinou-se então, o peso da matéria seca das várias partes da planta.

As pesagens foram realizadas em uma balança Mettler modelo PN 1200, com capacidade para 1200 gramas e precisão de 0,01 gramas.

\section{3 - RESULTADOS E DISCUSSÃo}

\subsection{Embebição das sementes}

Os resultados referentes a embebição das sementes do labe-labe, escarificadas e não escarificadas, submetidas a diferentes tempos de embebição, são apresentados no Quadro 2.

Os dados referentes ao tratamento absorção de água pelas sementes escarificadas, submetidas a 1, 8 e 16 horas de embebição, foram estatisticamente superiores quando comparados com 0 tratamento de sementes não escarificadas. Deve-se notar, que com apenas uma hora de imersão, as sementes escarificadas já apresentaram um acentuado aumento em peso e volume. A imersão por períodos mais prolongados não resultou em aumentos significativos na absorção de água pelas sementes. Entretanto, a analise do Quadro 2 revela que a escarificação favoreceu a absorção de água das sementes, que ficaram imersas por apenas 1 hora. 

crescimento inicial do labe-labe (Dolichos lab lab L. cV. RONGAI). PUBVET, Londrina, V. 6, N. 12, Ed. 199, Art. 1333, 2012.

QUADRO 2 - Peso e volume de 100 sementes de labe-labe, escarificadas e não escarificadas submetidas a diferentes tempos de embebição.

\begin{tabular}{|c|c|c|c|c|}
\hline \multirow{2}{*}{$\begin{array}{c}\text { Tempo de } \\
\text { Embebição } \\
(\text { Horas })\end{array}$} & \multicolumn{2}{|c|}{ Peso $(\mathrm{g})$} & \multicolumn{2}{c|}{ Volume $(\mathrm{ml})$} \\
\cline { 2 - 5 } & $\begin{array}{c}\text { Sementes } \\
\text { Escarificadas }\end{array}$ & $\begin{array}{c}\text { Sementes não } \\
\text { Escarificadas }\end{array}$ & $\begin{array}{c}\text { Sementes } \\
\text { Escarificadas }\end{array}$ & $\begin{array}{c}\text { Sementes não } \\
\text { Escarificadas }\end{array}$ \\
\hline 0 & $24,13 \mathrm{Ba} *$ & $22,47 \mathrm{Ba}$ & $19,00 \mathrm{Ca}$ & $17,75 \mathrm{Ba}$ \\
\hline 1 & $44,92 \mathrm{Aa}$ & $26,99 \mathrm{Bb}$ & $40,50 \mathrm{Ba}$ & $23,50 \mathrm{Bb}$ \\
\hline 8 & $49,38 \mathrm{Aa}$ & $45,11 \mathrm{Aa}$ & $44,50 \mathrm{ABa}$ & $41,00 \mathrm{Aa}$ \\
\hline 16 & $50,81 \mathrm{Aa}$ & $47,12 \mathrm{Aa}$ & $46,50 \mathrm{Aa}$ & $42,25 \mathrm{Aa}$ \\
\hline
\end{tabular}

*Médias seguidas das mesmas letras maiúsculas nas colunas e minúsculas nas linhas, não diferem estatisticamente entre si pelo Teste de Tukey $(P<0,01)$.

Para as sementes não escarificadas, o período da imersão por 8 a 16 horas resultou em acréscimos significativos na absorção de água.

A literatura consultada não revelou a necessidade de se escarificar as sementes do labe-labe, pois as mesmas absorvem água com facilidade. Por outro lado, os resultados obtidos sugerem, que a escarificação das sementes seguida da imersão por 1 hora, ou somente a imersão por 8 horas, poderia resultar em germinação mais rápida e uniforme, em decorrência do intumescimento prévio das sementes.

\subsection{Crescimento inicial}

A avaliação do crescimento inicial do labe-labe foi estudada através de contagens de plantas nos diferentes estádios de crescimento, já mencionados no item Material e Métodos, conforme demonstrado no Quadro 3.

Os dados referentes a primeira observação, realizada 8 dias após a semeadura, revelam, que independentemente da embebição e escarificação, as sementes do labe-labe apresentaram uma germinação bastante rápida e uniforme. Entretanto, foi observado, que tanto para as sementes escarificadas como para as não escarificadas, a embebição por 8 ou 16 horas, resultou em maior numero de plantas germinadas. 
QUADRO 3 - Numero total de plantas de labe-labe nos dois primeiros estádios de crescimento, decorridos nove dias após semeadura.

\begin{tabular}{|c|c|c|c|c|c|c|c|c|c|c|c|c|}
\hline \multirow{2}{*}{$\begin{array}{c}\text { Estádios } \\
\text { de }\end{array}$} & \multicolumn{10}{|c|}{ TRATAMENTOS } \\
\cline { 2 - 15 } Crescimento & NE & NE & NE & NE & NE & NE & E & E & E & E & E & E \\
\hline 10 & $16 \mathrm{~S}$ & $8 \mathrm{~S}$ & $8 \mathrm{P}$ & $1 \mathrm{~S}$ & $1 \mathrm{P}$ & $16 \mathrm{~S}$ & $16 \mathrm{P}$ & $8 \mathrm{~S}$ & $8 \mathrm{P}$ & $1 \mathrm{~S}$ & $1 \mathrm{P}$ \\
\hline $2^{\circ}$ & 8 & 9 & 13 & 9 & 6 & 5 & 10 & 10 & 14 & 9 & 9 & 8 \\
\hline
\end{tabular}

Legenda: E e NE - Sementes escarificadas e não escarificadas. 1, 8 e 16 - Tempo de embebição em horas. S e P - Ausência e Presença de adubação nitrogenada.

A análise do Quadro 4 mostra que o crescimento inicial do labelabe independentemente dos tratamentos testados, foi bastante vigoroso.

QUADRO 4 - Número total de plantas de labe-labe nos vários estádios de crescimento, decorridos 16 dias após semeadura.

\begin{tabular}{|c|c|c|c|c|c|c|c|c|c|c|c|c|}
\hline \multirow{2}{*}{$\begin{array}{c}\text { Estádios } \\
\text { de }\end{array}$} & \multicolumn{10}{|c|}{ TRATAMENTOS } \\
\cline { 2 - 14 } Crescimento & NE & NE & NE & NE & NE & NE & E & E & E & E & E & E \\
\hline 10 & $16 \mathrm{~S}$ & $16 \mathrm{P}$ & $8 \mathrm{~S}$ & $8 \mathrm{P}$ & $1 \mathrm{~S}$ & $1 \mathrm{P}$ & $16 \mathrm{~S}$ & $16 \mathrm{P}$ & $8 \mathrm{~S}$ & $8 \mathrm{P}$ & $1 \mathrm{~S}$ & $1 \mathrm{P}$ \\
\hline 20 & 1 & - & 1 & - & - & - & - & - & - & - & 1 & - \\
\hline $3^{\circ}$ & - & - & - & - & - & - & - & - & - & 1 & 1 & \\
\hline $4^{\circ}$ & 25 & 24 & 25 & 23 & 21 & 24 & 25 & 21 & 24 & 23 & 24 & 25 \\
\hline
\end{tabular}

Legenda: E e NE - Sementes escarificadas e não escarificadas. 1, 8 e 16 - Tempo de embebição em horas. S e P - Ausência e Presença de adubação nitrogenada.

Considerando a alta porcentagem de germinação obtida após 15 dias da semeadura e para melhor se avaliar o crescimento inicial do labe-labe, procedeu-se a um desbaste, seguindo-se, concomitantemente, adubação nitrogenada nessa ocasião.

As avaliações efetuadas 16 e 31 dias após a adubação nitrogenada são apresentadas nos Quadros 5 e 6, respectivamente. 
QUADRO 5 - Número total de plantas de labe-labe nos vários estádios de crescimento, decorridos 16 dias após adubação nitrogenada.

\begin{tabular}{|c|c|c|c|c|c|c|c|c|c|c|c|c|}
\hline \multirow{2}{*}{$\begin{array}{c}\text { Estádios } \\
\text { de } \\
\text { Crescimento }\end{array}$} & \multicolumn{10}{|c|}{ TRATAMENTO } \\
\cline { 2 - 16 } & NE & NE & NE & NE & NE & NE & E & E & E & E & E & E \\
\hline 10 & - & - & - & - & - & - & - & - & - & - & - & - \\
\hline 20 & - & - & - & - & - & - & - & - & - & - & - & - \\
\hline 30 & - & - & - & - & - & - & - & - & - & - & - & - \\
\hline 40 & - & - & - & 1 & - & - & - & 4 & 1 & 1 & - & - \\
\hline 50 & 11 & 14 & 13 & 12 & 15 & 13 & 12 & 9 & 11 & 11 & 12 & 9 \\
\hline 60 & 4 & 1 & 2 & 2 & - & 2 & 3 & 2 & 3 & 3 & 3 & 6 \\
\hline
\end{tabular}

Legenda: E e NE - Sementes escarificadas e não escarificadas. 1, 8 e 16 - Tempo de embebição em horas. S e P - Ausência e Presença de adubação nitrogenada.

Aparentemente, o nitrogênio não exerceu nenhum efeito sobre o crescimento das plantas. Todavia, confrontando-se os resultados apresentados nos Quadros 3 e 4 com os Quadros 5 e 6, verificando-se que as plantas mostraram um crescimento bastante acentuado após o desbaste. Tal fato pode ser atribuído a menor competição entre plantas por água, luz e nutrientes. Vale a pena mencionar que até os 46 dias após a germinação, as plantas que receberam nitrogênio em cobertura se mostraram mais verdes quando comparadas com aquelas não adubadas. Entretanto, por ocasião do encerramento do experimento, as plantas que não haviam recebido nitrogênio, se apresentavam visivelmente mais verde quando comparadas com as plantas adubadas, visualizados na Figura 2. 
QUADRO 6 - Número total de plantas de labe-labe nos vários estádios de crescimento, decorridos 30 dias após adubação nitrogenada.

\begin{tabular}{|c|c|c|c|c|c|c|c|c|c|c|c|c|}
\hline \multirow{3}{*}{$\begin{array}{c}\text { Estádios } \\
\text { de } \\
\text { Crescimento }\end{array}$} & \multicolumn{12}{|c|}{ TRATAMENTOS } \\
\hline & NE & NE & NE & NE & $\mathrm{NE}$ & NE & $E$ & $\mathrm{E}$ & $E$ & $E$ & $E$ & $E$ \\
\hline & $16 S$ & $16 P$ & $8 S$ & $8 P$ & $1 S$ & $1 P$ & $16 S$ & $16 P$ & $8 S$ & $8 P$ & $1 S$ & $1 P$ \\
\hline 10 & - & - & - & - & - & - & - & - & - & - & - & - \\
\hline 20 & - & - & - & - & - & - & - & - & - & - & - & - \\
\hline 30 & - & - & - & - & - & - & - & - & - & - & - & - \\
\hline 40 & - & - & - & - & - & - & - & - & - & - & - & - \\
\hline 50 & - & - & - & - & - & - & - & - & - & - & 2 & - \\
\hline 60 & - & - & - & - & 2 & 2 & - & 3 & - & - & - & 1 \\
\hline 70 & 12 & 13 & 14 & 13 & 13 & 13 & 14 & 4 & 9 & 7 & 10 & 9 \\
\hline $8^{\circ}$ & 3 & 2 & 1 & 2 & - & - & 1 & 8 & 6 & 8 & 3 & 5 \\
\hline
\end{tabular}

Legenda: E e NE - Sementes escarificadas e não escarificadas. 1, 8 e 16 - Tempo de embebição em horas. S e P - Ausência e Presença de adubação nitrogenada.

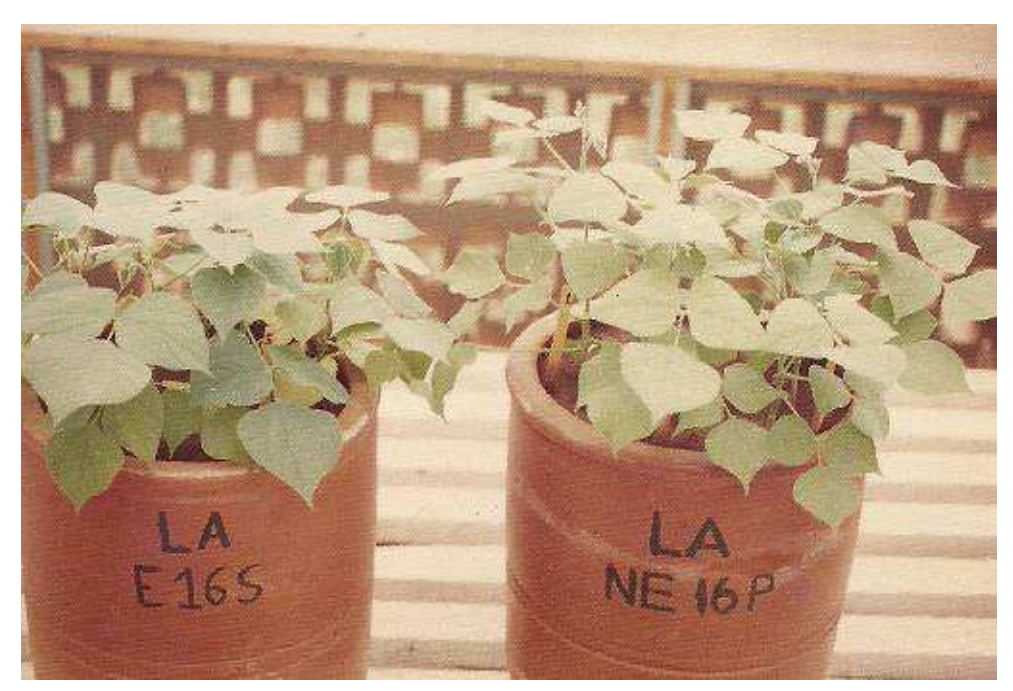

FIGURA 2 - Aspecto comparativo da coloração das plantas de labe-labe na ausência (S) e presença (P) de adubação nitrogenada (100 kg de N/ha), 61 dias após a semeadura.

Os resultados obtidos no presente experimento concordam com os de WHYTEMAN (1972), que aplicando $28 \mathrm{~kg}$ de N/ha, nove ou 18 dias após a 
semeadura, não observou efeito significativo no crescimento de soja perene e do siratro.

MATTOS \& CAMPOS (1975), trabalhando com a soja perene, também observaram, que aplicações de 15, 30 e $45 \mathrm{~kg}$ de $\mathrm{N} / \mathrm{ha}$ não afetaram o desenvolvimento inicial e nem a produção de matéria seca de plantas cultivadas em vasos.

Os dados apresentados no Quadro 7 se referem às avaliações efetuadas por ocasião do corte e refletem a uniformidade constatada no crescimento das plantas, conforme se observa na Figura 3.

QUADRO 7 - Número total de plantas de labe-labe nos vários estádios de crescimento, decorridos 60 dias após adubação nitrogenada.

\begin{tabular}{|c|c|c|c|c|c|c|c|c|c|c|c|c|}
\hline Estádios & \multicolumn{12}{|c|}{ TRATAMENTOS } \\
\hline de & $\mathrm{NE}$ & $\mathrm{NE}$ & NE & $\mathrm{NE}$ & NE & $\mathrm{NE}$ & $\mathrm{E}$ & $\mathrm{E}$ & $E$ & $E$ & $E$ & $E$ \\
\hline Crescimento & $16 \mathrm{~S}$ & $16 \mathrm{P}$ & 85 & $8 \mathrm{P}$ & $1 \mathrm{~S}$ & $1 \mathrm{P}$ & $16 S$ & $16 \mathrm{P}$ & $8 \mathrm{~S}$ & $8 \mathrm{P}$ & $1 \mathrm{~S}$ & $1 \mathrm{P}$ \\
\hline 10 & - & - & - & - & - & - & - & - & - & - & - & - \\
\hline 20 & - & - & - & - & - & - & - & - & - & - & - & - \\
\hline 30 & - & - & - & - & - & - & - & - & - & - & - & - \\
\hline 40 & - & - & - & - & - & - & - & - & - & - & - & - \\
\hline 50 & - & - & - & - & - & - & - & - & - & - & - & - \\
\hline $6^{\circ}$ & - & - & - & - & - & - & - & - & - & - & - & - \\
\hline 70 & - & - & - & - & - & - & - & 1 & - & - & - & - \\
\hline $8^{\circ}$ & - & - & - & - & 1 & - & - & - & - & 1 & 1 & 2 \\
\hline 90 & 5 & 7 & 8 & 7 & 10 & 6 & 5 & 4 & 8 & 2 & 4 & 4 \\
\hline $10^{\circ}$ & 10 & 8 & 7 & 8 & 4 & 9 & 10 & 10 & 7 & 12 & 10 & 9 \\
\hline
\end{tabular}

Legenda: E e NE - Sementes escarificadas e não escarificadas. 1, 8 e 16 - Tempo de embebição em horas. S e P - Ausência e Presença de adubação nitrogenada. 


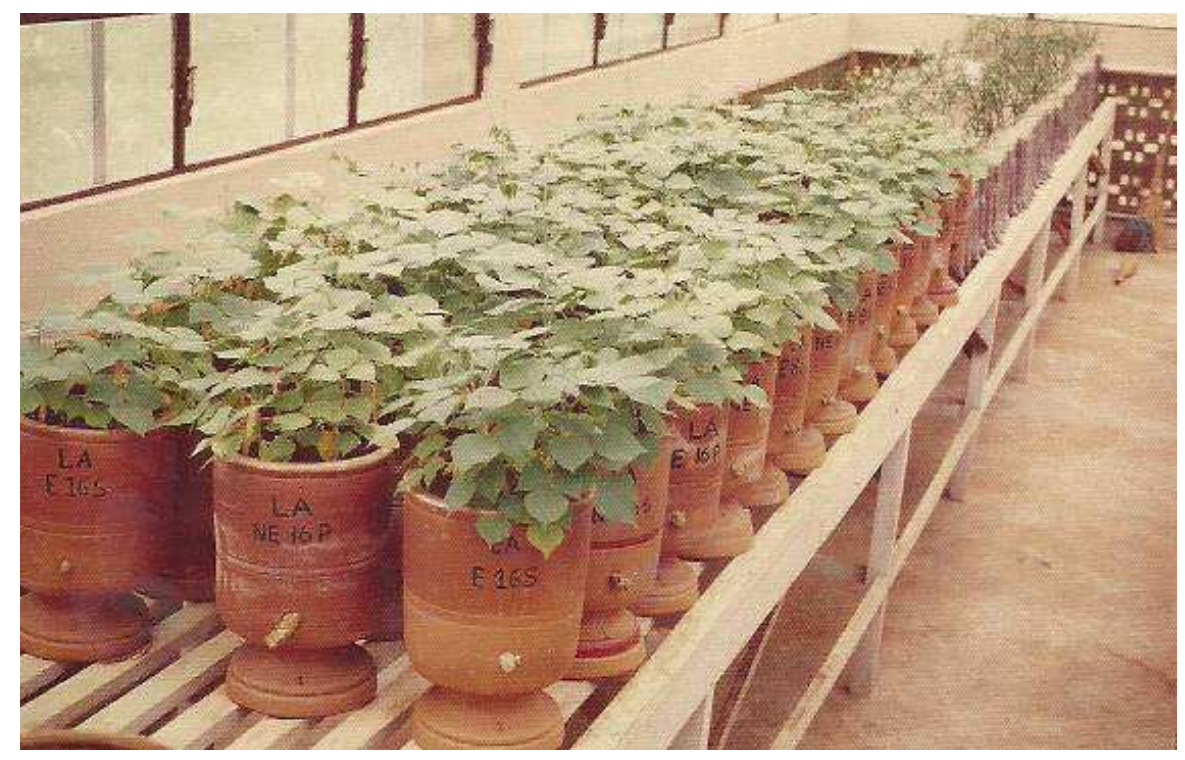

FIGURA 3 - Vista geral do experimento, evidenciando a uniformidade constatada no crescimento das plantas, 61 dias após a semeadura.

\subsection{Altura média das plantas}

A análise estatística dos dados referentes a altura média das plantas, determinada aos 16, 46 e 61 dias após a semeadura, mostrou que não ocorreram diferenças significativas entre os tratamentos. Na primeira medição a altura média das plantas foi bastante uniforme, independentemente dos tratamentos testados, conforme demonstrado no Quadro 8. Este fato pode ser atribuído á germinação rápida e uniforme das sementes do labe-labe; e também, porque nessa ocasião ainda não havia sido efetuada a adubação nitrogenada.

QUADRO 8 - Altura Média das plantas do labe-labe $(\mathrm{cm}), 16$ dias após a semeadura.

\begin{tabular}{|c|c|c|}
\hline \multirow{2}{*}{$\begin{array}{c}\text { TEMPO DE EMBEBIÇÃO } \\
\text { (HORAS) }\end{array}$} & \multicolumn{2}{|c|}{ TRATAMENTO DAS SEMENTES } \\
\cline { 2 - 3 } & $\mathrm{E}$ & $\mathrm{NE}$ \\
\hline 1 & 3,94 & 4,23 \\
\hline 8 & 3,80 & 3,85 \\
\hline 16 & 3,24 & 4,00 \\
\hline
\end{tabular}


Os dados referentes á segunda medição revelam que o nitrogênio aplicado não proporcionou um resultado satisfatório. Ao contrário do esperado, as plantas não adubadas apresentaram, de maneira geral, uma ligeira tendência para superar em altura as plantas que receberam adubação nitrogenada. Essa tendência das plantas não adubadas se apresentarem maiores do que as adubadas foi novamente constatada por ocasião da terceira medição em vários tratamentos, de acordo com os resultados apresentados (Quadro 9).

QUADRO 9 - Altura média das plantas do labe-labe $(\mathrm{cm}), 46$ e 61 dias após a semeadura.

\begin{tabular}{|c|c|c|c|c|}
\hline \multirow{2}{*}{$\begin{array}{c}\text { TEMPO DE } \\
\text { EMBEBIÇÃO }\end{array}$ (Horas) } & \multicolumn{5}{|c|}{ TRATAMENTOS DAS SEMENTES } \\
\cline { 2 - 5 } & $\mathrm{P}$ & $\mathrm{S}$ & $\mathrm{P}$ & $\mathrm{S}$ \\
\hline \multicolumn{5}{|c|}{ E6 dias após semeadura } \\
\hline 1 & 9,49 & 11,14 & 9,26 & 10,05 \\
\hline 8 & 9,36 & 8,57 & 8,93 & 9,66 \\
\hline 16 & 8,38 & 9,32 & 7,96 & 10,06 \\
\hline \multicolumn{5}{|c|}{61 dias após semeadura } \\
\hline 1 & 20,42 & 21,00 & 16,38 & 16,87 \\
\hline 8 & 19,85 & 15,46 & 16,96 & 18,57 \\
\hline 16 & 17,47 & 16,09 & 14,62 & 10,04 \\
\hline
\end{tabular}

$\mathrm{Na}$ ausência de nitrogênio, as plantas em nodulação satisfatória, conseguiram suprir suas exigências em nitrogênio e com isso superar em altura as plantas que receberam adubação nitrogenada. 


\subsection{Produção e Distribuição de matéria seca}

A análise estatística dos dados referentes a produção de matéria seca total do labe-labe ( $\mathrm{g} / 5$ plantas), após 61 dias de semadura, revelou que não foram significativas as diferenças entre tratamentos (Quadro 10).

QUADRO 10 - Produção de matéria seca do labe-labe ( $\mathrm{g} / 5$ plantas), 61 dias após a semeadura.

\begin{tabular}{|c|c|c|c|c|}
\hline \multirow{2}{*}{$\begin{array}{c}\text { TEMPO DE } \\
\text { EMBEBIÇÃO } \\
\text { (horas) }\end{array}$} & \multicolumn{2}{|c|}{ E } & \multicolumn{2}{c|}{ NE } \\
\cline { 2 - 5 } & $\mathrm{P}$ & $\mathrm{S}$ & $\mathrm{S}$ & \\
\hline 1 & $8,42 \mathrm{Aa}^{*}$ & $8,73 \mathrm{Aa}$ & $8,74 \mathrm{Aa}$ & $8,44 \mathrm{Aa}$ \\
\hline 8 & $8,99 \mathrm{Aa}$ & $7,28 \mathrm{Aa}$ & $8,64 \mathrm{Aa}$ & $9,16 \mathrm{Aa}$ \\
\hline 16 & $7,76 \mathrm{Aa}$ & $7,72 \mathrm{Aa}$ & $7,81 \mathrm{Aa}$ & $9,04 \mathrm{Aa}$ \\
\hline
\end{tabular}

Legenda: E e NE - Sementes escarificadas e não escarificadas. 1, 8 e 16 - Tempo de embebição em horas. S e P - Ausência e Presença de adubação nitrogenada.*Médias seguidas da mesma letra maiúscula na coluna a minúscula na linha, não diferem estatisticamente entre si pelo Teste de Tukey $(P<$ $0,01)$.

A produção e distribuição de matéria seca das várias partes da planta do labe-labe ( $\mathrm{g} / 5$ plantas), nos diferentes tratamentos, são apresentadas no Quadro 11.

Conquanto não se tenha feito a análise estatística da distribuição de matéria seca na parte aérea do labe-labe, a análise do Quadro 11 evidencia que a distribuição e produção de matéria seca nas diversas partes da planta, nos diferentes tratamentos, foi bastante uniforme.

Considerando-se a uniformidade inicial do crescimento e existência do mesmo número de plantas por vaso, poder-se-ia esperar que os tratamentos que receberam nitrogênio apresentassem maior produção de matéria seca. Segundo DONALD (1963), não havendo limitação de água e de luz, a competição se estabelece por falta de nutrientes.

O fato das plantas não adubadas apresentarem a mesma produção de matéria seca que as adubadas, admite a hipótese de que a aplicação de 
IAPICHINI, J.E.C.B. et al. Efeito da escarificação, da embebição e da adubação nitrogenada no crescimento inicial do labe-labe (Dolichos lab lab L. cv. RONGAI). PUBVET, Londrina, V. 6, N. 12, Ed. 199, Art. 1333, 2012.

nitrogênio 16 dias após a semeadura, tenha prejudicado a nodulação e o consequente desenvolvimento das plantas adubadas.

QUADRO 11 - Produção e distribuição de matéria seca das várias partes labelabe ( $\mathrm{g} / 5$ plantas), após 61 dias da semeadura.

\begin{tabular}{|c|c|c|c|c|c|c|c|c|}
\hline \multirow[t]{2}{*}{ TRATAMENTOS } & \multicolumn{8}{|c|}{ P DA MATÉRIA SECA (g/5 Plantas) } \\
\hline & $\begin{array}{l}\text { Folhas } \\
\text { mais novas }\end{array}$ & $\begin{array}{l}\text { Folhas } \\
\text { senescentes }\end{array}$ & Pecíolos & Caule & $\begin{array}{l}\text { Total da } \\
\text { Parte Aérea }\end{array}$ & Raizes & Nódulos & $\begin{array}{l}\text { Total do } \\
\text { sistema } \\
\text { radicular }\end{array}$ \\
\hline NE16S & 3,83 & 0,09 & 0,73 & 1,87 & 6,52 & 2,01 & 0,51 & 2,52 \\
\hline NE16P & 3,26 & 0,06 & 0,64 & 1,61 & 5,56 & 2,13 & 0,12 & 2,25 \\
\hline NE8S & 3,68 & 0,15 & 0,73 & 1,91 & 6,47 & 2,10 & 0,59 & 2,68 \\
\hline NE8P & 3,67 & 0,19 & 0,77 & 2,01 & 6,63 & 1,90 & 0,11 & 2,01 \\
\hline NE1S & 3,40 & 0,08 & 0,66 & 1,76 & 5,91 & 2,09 & 0,44 & 2,53 \\
\hline NE1P & 3,25 & 0,21 & 0,70 & 1,97 & 6,13 & 2,50 & 0,11 & 2,61 \\
\hline E16S & 3,12 & 0,32 & 0,66 & 1,57 & 5,67 & 1,65 & 0,40 & 2,05 \\
\hline $\mathrm{E} 16 \mathrm{P}$ & 3,39 & 0,10 & 0,82 & 1,80 & 6,11 & 1,59 & 0,06 & 1,65 \\
\hline E8S & 3,03 & 0,20 & 0,58 & 1,48 & 5,39 & 1,61 & 0,38 & 1,99 \\
\hline E8P & 3,85 & 0,17 & 0,83 & 2,33 & 7,17 & 1,73 & 0,09 & 1,82 \\
\hline E1S & 3,85 & 0,19 & 0,69 & 2,07 & 6,80 & 1,49 & 0,44 & 1,93 \\
\hline E1P & 3,40 & 0,17 & 0,75 & 1,98 & 6,29 & 2,00 & 0,13 & 2,13 \\
\hline
\end{tabular}

Os dados apresentados no Quadro 12 revelam que a aplicação de nitrogênio prejudicou significativamente a nodulação das plantas do labe-labe.

QUADRO 12 - Efeito do nitrogênio sobre a massa nodular do labe-labe.

\begin{tabular}{|l|l|l|}
\hline \multirow{2}{*}{ ADUBAÇÃO } & \multicolumn{2}{|l|}{ TRATAMENTO DA SEMENTES } \\
\cline { 2 - 3 } & E & NE \\
\hline $\mathrm{S}$ & $1,99 \mathrm{Aa}^{*}$ & $0,51 \mathrm{Ab}$ \\
\hline $\mathrm{P}$ & $0,09 \mathrm{Ba}$ & $0,11 \mathrm{Ba}$ \\
\hline
\end{tabular}

* Médias seguidas da mesma letra maiúscula na coluna e minúscula na linha, não diferem estatisticamente entre si, pelo teste de Tukey $(P<0,05)$. 
Os dados obtidos suportam os resultados relatados por ALLOS \& BARTHOLOMEW (1959) e CARAMBULA (1967), que trabalhando com leguminosas de clima temperado, verificaram um efeito depressivo da aplicação de nitrogênio sobre a nodulação das plantas.

GATES (1970) verificou que em níveis adequados de fósforo, a adição de até $75 \mathrm{~kg}$ de nitrogênio não afetou a nodulação da Leucaena leucocephala (Lam.) de Wit, mas que, na ausência do fósforo, a formação de nódulos foi inibida.

Por outro lado, WHYTEMAN (1972) constatou que a aplicação de 28 $\mathrm{kg} \mathrm{N} / \mathrm{ha}, 9$ ou 18 dias após a semeadura, não prejudicou nem o crescimento, nem a nodulação de soja perene e siratro.

Aplicações de 15, 30 e $45 \mathrm{~kg}$ de N/ha, no plantio ou parceladas, não afetaram o crescimento inicial e a nodulação da soja perene (MATTOS \& CAMPOS, 1975).

\section{4 - CONCLUSÕES}

Os resultados obtidos mostraram que a escarificação das sementes seguida da imersão por 1 hora, ou somente a imersão por 8 horas, poderia resultar em germinação mais rápida.

O crescimento inicial do labe-labe, independentemente dos tratamentos testados, foi bastante vigoroso.

A altura média das plantas não variou em função dos diferentes tratamentos.

A distribuição e a produção de matéria seca na parte aérea da planta, após 61 dias da semeadura, foi bastante uniforme nos diferentes tratamentos.

A aplicação de nitrogênio, 16 dias após a semeadura, prejudicou significativamente o peso seco dos nódulos.

A introdução e multiplicação da cultura do Labe-labe pode ser incrementada de modo altamente exequível na agricultura familiar ou empresarial através de técnicas de baixo custo, contribuindo de forma 
IAPICHINI, J.E.C.B. et al. Efeito da escarificação, da embebição e da adubação nitrogenada no crescimento inicial do labe-labe (Dolichos lab lab L. cv. RONGAI). PUBVET, Londrina, V. 6, N. 12, Ed. 199, Art. 1333, 2012.

marcante na sustentabilidade de diferentes sistemas de produção animal e vegetal e ainda em programas de segurança alimentar humana.

\section{5 - BIBLIOGRAFIA}

ALLOS, H.P. \& BARTOLOMEW, W.V, Replacement of symbiotic fixation by available nitrogen. Soil. $\underline{\text { Sci., }}$ 87(2): 61-6, 1959.

CARÁBULA, M. Effects of inorganic $\mathrm{N}$ on growth and nodulation of Medicago hiapida var. confinie). Boln, téc. Estc. Exp. Paysandú, 4(3): 59-65, 1967. In: Herb. Abstr., 39(3) 1635, 1969.

COOKSLEY, D.G. A study of preplantig herbicides, nitrogen, burning and post-emergency cultivation on the establishment of Leucaena leucocephala cv. Peru. QD. ‥ agric. Anim. Sci., 31(3): 271-8, 1974.

CRUZ, G. R. B.; MATOS, V. P.; GONÇALVES, E. P. 1997. Germinação de sementes de araçá (Psidium araça Raddi-Myrtaceae): Tratamentos pré-germinativos. Informativo ABRATES, 7 (1/2): 259.

DONALD, C.M. Competition among crop and pasture plants. Adv.Agron., 15: 1-118, 1963.

GATES, C.T. Physiological aspects of the rhizobial symbiosis in Stylosanthes humilis, Leucaena leucochephala and Phaseolus atropurpureus. In: INTERNATIONAL GRASSLAND CONGRESS, 11, Surfers Paradise, Austrália, 1970. Proceedings, p.442-6.

HERMANSEN, L. A.; DURYEA, M. L.; WHITE, T. L. 2000. Variability in seed coat dormancy in Dimorphandra mollis. Seed Science Technology, 28 (3): 567-580.

LULA, A. A.; AlvarengA, A. A.; AlmeidA, L. P.; Alves, J. D.; MAGAlHÃ, M. M. 2000. Estudos de agentes químicos na quebra de dormência de sementes de Paspalum paniculatum L. Ciências e Agrotecnologia, 24 (2): 358-366.

McDONALD, M. B.; COPELAND, L. O. 1997. Seed production: Principles and practices. Chapmam e Hall, New Jersey, USA, 749pp.

MARCOS FILHO, M. Fisiologia de sementes de plantas cultivadas. Piracicaba: FEALQ, 2005. 495p.

MATTOS, H.B. \& CAMPOS, B.E.S. Efeito de aplicação de nitrogênio no desenvolvimento de

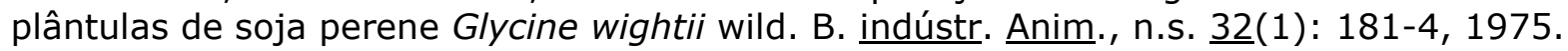

NATIONAL ACADEMY OF SCIENCES: TROPICAL LEGUMES: Resources for the Future. Washington, D.C. 1979. 331p.

SANTARÉM, E. R.; ÁQUILA, M. E. A. 1995. Influência de métodos de superação de dormência e do armazenamento na germinação de sementes de Senna macranthera (Colladon) Irwin e Barneby (Leguminosae). Revista Brasileira de Sementes, 17 (2): 205-209.

SANTOS, T. O.; MORAIS, T. G. O.; MATOS, V. P. 2004. Escarificação mecânica em sementes de chichá (Sterculia foetida L.). Revista Árvore, 28 (1): 1-6.

SILVA, L. M. M.; MATOS, V. P. 1993. Estudo sobre dormência de sementes de mulungu (Erythrina velutina Willd.): viabilidade e presença de inibidores. Ciência Agrícola, 2 (1): 29-40. 
SOUTO, S.M \& DOBEREINER, J. Problems in the establishment of perennial soybean (Glycine javanica L.) in a tropical region. In: INTERNATIONAL GRASSLAND CONGRESS, 11., Surfers Paradise, Austrália, 1970. Proccedings, p.127-31.

WHYTEMAN, P.C. The effects of inoculation and nitrogen application on seedling growth and nodulation of Glycine withtii and Phaseolus atropurpureus in the field. Trop. Grassl., $\underline{6}(1)$ : 11$6,1972$.

VEIGA, et al. Avaliação dos Aspectos Florísticos de uma Mata Ciliar no Norte do Estado do Paraná. Revista Acta Scientiaum Agronomy. V. 25 n.2. 2003. 